\title{
NILAI-NILAI KEBAJIKAN: \\ KEBAIKAN HATI, LOYALITAS, DAN KESALEHAN DALAM KONTEKS BUDAYA MELAYU
}

\author{
Dede Fitriana Anatassia ${ }^{1, a}$, \\ Mirra Noor Milla, \\ Subhan El Hafiz \\ ${ }^{a}$ Fakultas Psikologi \\ Universitas Islam Negeri Sultan Syarif Kasim Riau \\ Jl. H.R. Soebrantas No. 155 KM 15 Simpang Baru Panam \\ Pekanbaru 28293, Indonesia \\ ${ }^{b}$ Fakultas Psikologi \\ Universitas Muhammadiyah Prof. Dr. Hamka \\ Jl. Limau 2 Kebayoran Baru \\ Jakarta, Indonesia \\ ${ }^{1}$ e-mail: dede.fitriana@gmail.com \\ 2e-mail:subhanhafiz@gmail.com
}

\begin{abstract}
The belief in good values that live in the community have an influence on the individual's behavior. Virtue is one of them. Virtues found to have links with the individual's character and personality. By using the approach of constructive realism indigenous psychology, this study aims to explore the virtues in the context of Melayu culture. Data collection techniques in this study were open ended questions and multiple responses. Data were analyzed with qualitative and quantitative methods using NVivo. It was found that kindness and loyalty are the core virtues that are considered important in everyday life. In the relationship context, the behaviors target of these values is higher in the community than personal. Virtues was found to be differ according to the demands of the situation. These virtues shifted in problem solving situations, where kindness and empathy are expected to appear less than serenity and resourceful. It is clear that the virtues which embraced by the individual does not always manifest if the situation is not supportive for the emergence of these virtues.
\end{abstract}

Keywords: kindness; loyalty; virtues; relation

\footnotetext{
Abstrak-Kepercayaan pada nilai-nilai kebaikan yang hidup dalam masyarakat memiliki pengaruh pada perilaku individu. Nilai-nilai kebajikan adalah salah satunya. Nilai kebajikan ditemukan memiliki kaitan dengan karakter dan kepribadian seseorang. Dengan menggunakan pendekatan realisme konstruktif indigenous psychology, studi ini bertujuan menggali nilai-nilai kebajikan dalam konteks budaya Melayu. Penelitian ini menggunakan teknik pengumpulan data open ended question dan multi respon. Data
} 
dianalisis dengan metode kualitatif dan kuantitatif dengan menggunakan NVivo. Ditemukan bahwa nilai-nilai kebaikan hati dan loyalitas merupakan nilai-nilai utama yang dianggap penting dalam kehidupan sehari-hari. Dalam konteks relasi, target pengamalan perilaku dari nilai-nilai tersebut lebih tinggi pada komunitas dibandingkan personal. Nilai-nilai kebajikan ditemukan berbeda sesuai dengan tuntutan situasi. Nilai-nilai tersebut bergeser dalam situasi penyelesaian masalah, dimana kebaikan hati dan empati lebih sedikit diharapkan muncul dibandingkan ketenangan (serenity) dan kepandaian (resourceful). Hal ini menjelaskan bahwa nilai-nilai yang dianut oleh individu tidak selalu manifes jika situasinya tidak mendukung bagi munculnya nilai tersebut.

Kata kunci: kebaikan hati; loyalitas; kebajikan; relasi

\section{PENDAHULUAN}

Nilai-nilai kebajikan (virtue) sepanjang sejarah kehidupan manusia telah banyak diteliti dalam satu dekade terakhir. Pada awalnya, nilai-nilai kebajikan merupakan kajian moral di dalam Filsafat (Haidt \& Joseph, 2004; Haidt, 2012; Cornwell, 2014). Dalam Psikologi, upaya untuk menemukan kekuatan dan potensi tertinggi manusia ini sesungguhnya sudah menjadi perhatian utama Seligman (2002) dalam mengembangkan psikologi positif. Dalam kaitannya dengan kebajikan, Fowers (2005) menjelaskan bahwa kebajikan dalam psikologi secara efektif dapat dikarakterisasikan sebagai interaksi dari kehormatan (dignity), kesejahteraan (well being) dan integritas.

Diketahui bahwa setiap masyarakat mengembangkan dan mengajarkan nilai-nilai kebajikan secara turun temurun. Dalam hal ini nilai-nilai kebajikan ada yang bersifat universal dan ada yang bersifat spesifik sesuai dengan konteks budaya tertentu (Oudenhoven, Raad, Timmerman, Askevis-Leherpeux, Boski, Carmona, Choubisa, Domingusez, Bye, Kurylo, Lahmann, Mastor, Selenko, Slezackova, Smith, Tip, \& Yik, 2014). Dengan kata lain, masing-masing suku bangsa maupun kelompok etnis mungkin mengembangkan kebajikan yang berbeda dimana nilai kebajikan tertentu lebih menonjol pada kelompok suku/bangsa/etnis tertentu dibandingkan yang lain (Seligman, 2002). Penelitian yang dilakukan pada beberapa kelompok budaya dalam peradaban manusia kemudian melahirkan beberapa klasifikasi mengenai nilai-nilai kebajikan. Salah satunya adalah klasifikasi enam nilai kebajikan oleh Peterson dan Seligman (2004). Menurut mereka, nilai-nilai kebajikan diklasifikasikan dalam enam nilai yaitu kebijaksanaan (wisdom), keberanian (courage), kebaikan hati (humanity), keadilan (justice), kesabaran (temperance) dan kesalihan (transcendence).

Sebagai salah satu dari nilai kebajikan, kebijaksanaan dan pengetahuan dapat diterangkan sebagai kekuatan kognitif yang berkaitan dengan proses pemerolehan dan penggunaan pengetahuan (Peterson and Seligman, 2004; Kramer, 2000; Shryack, Steger, Krueger, \& Kallie, 2010; Oudenhoven, Raad, Carmona, Helbig, \& Linden, 2012). Salah satu nilai kebajikan dalam kebijaksanaan dapat dilihat dari sejarah peradaban Buddha yang memiliki dua elemen penting dalam hidup yaitu kebijaksanaan 
dan etika (Walshe, 1995). Sementara pada masyarakat China kuno, kebijaksanaan dan kecerdasan merupakan salah satu prinsip dasar confician yang dikenal dengan nama zhi (Dahlsgaard, Peterson, \& Seligman, 2005).

Selain kebijaksanaan, keberanian adalah nilai-nilai kebajikan yang dimiliki oleh berbagai kelompok budaya, meskipun nilai keberanian tidak konsisten muncul dalam peradaban manusia (Dahlsgaard, dkk, 2005). Keberanian diperlukan sebagai kekuatan emosional untuk mencapai tujuan dalam menghadapi tantangan, baik eksternal maupun internal (Peterson \& Seligman, 2004). Selain itu, keberanian merupakan kekuatan intelektual dalam menghadapi berbagai tantangan dalam kehidupan (Baehr, 2013; Shryack, dkk, 2010; Fowers, 2014)

Salah satu nilai kebajikan yang erat kaitannya dengan relasi interpersonal adalah kebaikan hati. Kebaikan hati merupakan kekuatan dalam relasi interpersonal yang berhubungan dengan keinginan untuk merawat dan membangun persahabatan dengan orang lain (Peterson \& Seligman, 2004). Dalam beberapa penelitian nilai kebajikan ini diistilahkan berbeda, seperti empati (Cawley, Martin, \& Johnson, 2003), kebaikan (kind) (Fowers, 2014), dan belas kasih (compassion) (Haidt \& Joseph, 2004).

Nilai kebajikan yang berkaitan dengan komitmen pada komunitas adalah keadilan (Fowers, 2014, Shryack dkk, 2010; Oudenhoven dkk, 2012). Keadilan merupakan kekuatan masyarakat yang mendasari terwujudnya kehidupan bermasyarakat yang sehat. Keadilan menjadi salah satu prinsip dasar ajaran confucian, yaitu yi yang berarti kesetaraan/keadilan (Dahlsgaard, dkk, 2005).

Nilai kebajikan selanjutnya adalah kesabaran. Nilai kebajikan ini merupakan kekuatan yang berkaitan dengan pemaafan dan belas kasih (Peterson \& Seligman, 2004; Emmons, 2003). Dalam ajaran Buddha, nilai kebajikan ini disebut upeksa yang berarti ketenangan (Dahlsgaard, dkk, 2005). Nilai kebajikan ini merupakan nilai menjaga diri untuk tetap tenang, tabah, menerima dan berdamai dengan segala permasalahan baik dengan orang lain maupun dengan dunia (Cawley dkk, 2003). Di dalam ajaran Islam, Quraish Shihab di dalam $T_{s} f s i r$ Al Misbah, kesabaran memiliki makna dasar menahan dan dalam kajian psikologi, kesabaran dalam Islam bermakna kemampuan untuk menahan emosi, pikiran, perkataan, dan perbuatan yang bertujuan untuk kebaikan namun tetap taat pada aturan (E1 Hafiz, Mundzir, Pratiwi, \& Rozi, 2013).

Sementara nilai kebajikan yang berkaitan dengan hubungan manusia dengan Tuhan adalah kesalihan. Menurut Peterson \& Seligman (2004), kesalihan merupakan kekuatan yang membentuk hubungan individu dengan alam semesta dan memberikan makna dalam kehidupan individu. Nilainilai kesalihan dapat bersumber dari ajaran/kebudayaan, seperti ajaran Tao (Dahlsgaard, dkk, 2005), maupun agama (Schnall, Schiffman, \& Cherniak, 2014).

Nilai-nilai kebajikan adalah karakteristik dasar yang dinilai oleh filsuf moral dan cendekia agama. Sebagai tema yang awalnya banyak dikembangkan dalam kajian filsafat, oleh para filsuf nilai- 
nilai kebajikan diyakini bersifat stabil dan reliabel dan derivasi nilai kebajikan ini lebih tepat disebut sebagai karakter (Annas, 2003; Fowers, 2012). Menurut Dahlsgaard, dkk (2005), setiap nilai kebajikan terwujud dalam karakter utama yang bisa diadopsi setiap manusia dan dituangkan dalam perilaku sehari-hari. Karakter utama adalah proses dan mekanisme psikologis yang mendefinisikan nilai-nilai kebajikan. Kebajikan yang hidup dalam masyarakat selanjutnya akan dianut oleh individu-individu dengan 'mengikat' diri (self) mereka dengan nilai-nilai 'kebaikan' dan 'hal-hal yang dianggap baik' .

Namun demikian, pendapat lain menyatakan nilai-nilai kebajikan dalam Psikologi lebih tepat dibahas dengan pendekatan kepribadian bukan karakter. Allport (1937) menyatakan bahwa karakter adalah istilah yang lebih relevan dengan kajian etika dibandingkan kajian Psikologi. Karakter dievaluasi melalui kepribadian, sementara kepribadian berasal dari karakter (Cawley, dkk, 2000).

Manifestasi dari nilai kebajikan dapat terwujud dalam berbagai bentuk, tergantung dari konteks sosial (Benkler \& Nissenbaum, 2006). Hal ini menjelaskan bahwa konteks sosial tertentu akan memicu munculnya nilai kebajikan tertentu. Kondisi ini menjadi perdebatan yang menarik. Kaum situasionis menyatakan betapa besarnya peran situasi dalam menentukan nilai kebajikan yang akan muncul, sementara filsuf kebajikan kuno menegaskan bahwa nilai kebajikan bersifat konsisten dan ajeg. Dengan kata lain, nilai kebajikan tidak bergantung dari situasi atau konteks sosial dimana individu berada (Kamtekar, 2004; Jost \& Jost, 2009). Jika seorang individu memiliki nilai kejujuran, maka menurut filsuf kebajikan kuno, dalam situasi apa pun individu tersebut akan berkata dan berperilaku jujur, sementara kalangan psikologi sosial menyatakan belum tentu individu yang memiliki nilai kejujuran mampu menampilkan perilaku jujur dalam setiap tingkah laku di berbagai situasi.

Berdasarkan pemaparan di atas, nilai kebajikan merupakan kajian menarik yang masih belum banyak dikembangkan dalam penelitian Psikologi. Penelitian ini bermaksud untuk menggali nilai-nilai kebajikan pada konteks budaya Melayu. Nilai-nilai kebajikan yang dimaksud akan dikonstruksi dari sifat dan perilaku yang dianggap baik dalam masyarakat. Selanjutnya, penelitian ini juga bertujuan untuk mengetahui peran situasi dalam perwujudan nilai-nilai kebajikan pada masyarakat Melayu, terlebih untuk mengetahui apakah pada situasi spesifik akan memunculkan nilai kebajikan yang berbeda.

\section{METODE}

\section{Partisipan}

Partisipan dalam penelitian ini merupakan mahasiswa Psikologi UIN Sultan Syarif Kasim Riau yang berjumlah 137 responden. Teknik sampling yang digunakan adalah non random sampling. Karakteristik responden adalah individu yang lahir atau memiliki tempat tinggal di wilayah Melayu Riau. 


\section{Desain}

Penelitian ini menggunakan metode kualitatif realism konstruktif dengan pendekatan indigenous psychology. Realisme konstruktif adalah pendekatan dalam membentuk konstrak berdasarkan realitas yang ada dalam masyarakat. Oleh karena itu, kajian tidak terlalu bergantung dengan konsep teori yang berkembang akan tetapi lebih bersumber dari pengalaman individu dalam kehidupan sehari-hari. Hal ini berdasarkan asumsi bahwa konsep-konsep teori akan berbeda dan bergantung dengan konteks sosial budaya dan lingkungan dimana individu hidup.

\section{Prosedur}

Teknik pengumpulan data menggunakan kuesioner (open ended question). Kuesioner berisi empat pertanyaan terbuka, yang meliputi: (1) Sebutkan lima sifat orang yang baik menurut Anda! (2) Sebutkan salah seorang yang Anda kenal baik di dalam masyarakat, (3) Mengapa Anda menilai demikian (alasan pemilihan orang tersebut), (4) Nilai-nilai apa saja yang dimiliki orang tersebut dalam menyelesaikan berbagai masalah hidup sehari-hari. Sebelum digunakan kuesioner tersebut telah lebih dahulu diujicobakan, penilaian validitas dilakukan dengan melihat kesesuaian antara pertanyaan dengan jawaban yang diharapkan.

\section{Teknik Analisis}

Analisis data dilakukan dalam dua tahap. Tahap pertama yaitu tahap kualitatif. Pada tahapan ini, data yang terkumpul dikoding dan dikategorisasi sehingga memunculkan beberapa kategori besar. Dalam analisis menggunakan pendekatan multi respon, artinya jumlah yang dihitung adalah jumlah respon bukan dari jumlah subjek sehingga satu subjek bias saja memberikan lebih dari satu respon. Tahap kualitatif menggunakan program NVivo 8.0. Tahap kedua yaitu tahap kuantitatif. Tahap kuantitatif yang dimaksud berupa statistik deskriptif yaitu persentase setiap kategori dan tabulasi silang dari beberapa kategori yang muncul pada tahap pertama.

\section{ANALISIS DAN HASIL}

Pertanyaan pertama pada kuesioner adalah sifat-sifat orang yang baik dalam lingkungan masyarakat. Setiap responden diminta menuliskan lima sifat baik. Kategorisasi pada bagian ini menyesuaikan dengan enam klasifikasi kebajikan oleh Peterson dan Seligman (2004). Sebaran data pada setiap kategori akan dijelaskan pada tabel 1 di bawah ini. 
Tabel 1.

Kategori Sifat Baik

\begin{tabular}{clcc}
\hline No & \multicolumn{1}{c}{ Kategori } & Jumlah & Persentase \\
\hline 1 & Kebaikan Hati & 390 & 59,43 \\
2 & Keberanian & 133 & 19,42 \\
3 & Keadilan & 65 & 9,49 \\
4 & Kesabaran & 65 & 9,49 \\
5 & Kesalihan & 25 & 3,65 \\
6 & Kebijaksanaan & 7 & 1,02 \\
\hline & Total & 685 & 100 \\
\hline
\end{tabular}

Kebaikan Hati muncul sebagai karakter tertinggi dari hasil penelitian ini. Kebaikan Hati yang dimaksud dalam penelitian ini adalah segala sikap/perilaku positif yang ditujukan untuk orang lain, baik kepada orang yang dikenal maupun orang asing. Kebaikan Hati ditujukan sebagai alat/cara seseorang dalam membangun relasi sosial. Kebaikan Hati bisa dikatakan sebagai karakter yang paling utama karena besaran frekuensi/persentase yang melebihi separuh dari total respon. Hal ini menunjukkan, bahwa nilai kebajikan utama, yang juga merupakan nilai kebajikan yang paling umum dari masyarakat Melayu adalah Kebaikan Hati. Sifat dan perilaku yang termasuk dalam Kebaikan Hati yang dimaksud yaitu ramah, menolong, sopan, peduli, menghormati, memberi, baik dan terbuka. Turunan dari Kebaikan Hati yang cukup banyak ini agaknya menunjukkan bahwa baik hati dianggap mewakili banyak virtue sehingga mendapat proporsi yang lebih besar. Selanjutnya secara berurutan yaitu Keberanian, Keadilan, Kesabaran, Kesalihan dan Kebijaksanaan. Kesalihan dan Kebijaksanaan merupakan karakter terendah yang ditemui pada responden.

Pada pertanyaan keempat, responden diminta untuk menuliskan nilai-nilai apa saja yang dibutuhkan ketika menghadapi masalah dalam kehidupan sehari-hari. Pemberian konteks pada pertanyaan ini dimaksudkan untuk menguji peran situasi khusus dalam hubungannya dengan nilai kebajikan. Berikut akan dijelaskan kategori nilai-nilai kebajikan dalam penyelesaian masalah pada tabel 2 di bawah.

Tabel 2.

Kategori Nilai-nilai Kebajikan dalam Penyelesaian Masalah

\begin{tabular}{clcc}
\hline No & \multicolumn{1}{c}{ Kategori } & Jumlah & Persentase \\
\hline 1 & Kesabaran & 64 & 32,82 \\
2 & Kecerdasan & 58 & 29,74 \\
3 & Kasih Sayang & 34 & 17,44 \\
4 & Kebijaksanaan & 26 & 13,33 \\
5 & Ketaatan & 13 & 6,67 \\
\hline & Total & 195 & 100 \\
\hline
\end{tabular}


Kesabaran dan Kecerdasan muncul sebagai nilai kebajikan terpenting yang dibutuhkan dalam penyelesaian masalah. Kesabaran akan mengatasi kondisi emosional individu yang terlibat masalah, sementara Kecerdasan adalah upaya berpikir secara logis, sistematis, dan solutif untuk memecahkan masalah yang dihadapi. Sementara itu, meskipun tidak sedominan dua nilai sebelumnya, nilainilai kebajikan yang lain tetap muncul, yaitu Kasih Sayang, Kebijaksanaan dan Ketaatan. Hasil ini menunjukkan bahwa nilai-nilai kebajikan yang dimiliki individu tidaklah berbeda, namun dinamika dari nilai-nilai tersebut akan tergantung dari situasi yang dialami individu. Pada situasi tertentu nilai yang satu akan lebih dominan daripada nilai yang lain.

Hasil penelitian ini kembali menegaskan nilai-nilai kebajikan pada situasi umum akan berbeda pada situasi spesifik. Meskipun komponen nilai-nilai kebajikan tidaklah jauh berbeda, akan tetapi variasi terletak pada kekuatan masing-masing nilai. Pada situasi penyelesaian masalah, nilai-nilai terkait dengan Kesabaran dan Kecerdasan muncul sebagai dua nilai utama yang harus digunakan. Sementara pada situasi umum, nilai yang utama adalah Kebaikan Hati.

Pertanyaan kedua, responden diminta untuk menuliskan satu nama yang dianggap sebagai orang baik dalam masyarakat. Kemudian responden diminta untuk memberikan alasan atas penilaiannya tersebut. Hasil analisis dijelaskan pada tabel 3.

Tabel 3.

Kategori Orang Baik dalam Masyarakat

\begin{tabular}{llcc}
\hline No & \multicolumn{1}{c}{ Kategori } & Jumlah & Persentase \\
\hline $\mathbf{1}$ & Baik Hati & $\mathbf{1 8 5}$ & $\mathbf{7 0 , 6 1}$ \\
& a. Penolong & 55 & 20,99 \\
& b. Ramah & 52 & 19,85 \\
& c. Tabligh & 48 & 18,32 \\
& d. Soleh & 24 & 9,16 \\
& e. Cerdas & 6 & 2,29 \\
Loyal & a. Agensi & $\mathbf{7 7}$ & $\mathbf{2 3 , 3 9}$ \\
& b. Amanah & 41 & 15,65 \\
& c. Persekutuan (communion) & 21 & 8,02 \\
\hline & Total & 15 & 5,73 \\
\hline
\end{tabular}

Orang baik didefinisikan sebagai orang yang baik hatinya. Hal ini sesuai dengan hasil kategori untuk pertanyaan pertama. Perbedaannya adalah pada pertanyaan pertama, individu diminta untuk memberikan lima sifat baik secara hipotetis. Artinya individu diminta untuk menggambarkan kondisi ideal seseorang yang dianggap baik. Sementara pada pertanyaan ini, responden diminta untuk menilai orang lain yang dianggap baik. Orang lain yang dimaksud adalah orang yang dikenal oleh responden, 
sehingga penilaian yang dilakukan berdasarkan pengalamannya bersama orang tersebut. Dengan kata lain, pertanyaan ketiga merupakan konstruk yang terlahir dari pengalaman responden.

Dua kategori utama pada bagian ini yaitu Kebaikan Hati dan Loyalitas. Kebaikan Hati yang dimaksud adalah segala tindakan yang dimunculkan individu murni atas kepedulian dan niat untuk membantu orang lain, baik orang yang dikenal maupun orang yang tidak dikenal. Sementara Loyalitas, mengacu kepada segala bentuk kebaikan yang dilakukan individu didasarkan pada tugas, kewajiban dan tanggung jawab yang melekat padanya. Sehingga Loyalitas tidaklah berasal dari sifat personal individu melainkan konteks situasi dimana individu tersebut berada.

Pada respon yang sama, kemudian juga dianalisis target perilaku/sifat baik yang dijelaskan oleh responden. Secara umum dibagi dalam dua kategori yaitu Komunitas dan Personal. Analisis sebaran data bisa dilihat pada tabel 4 .

Tabel 4.

Kategori Target Perilaku Baik

\begin{tabular}{clcc}
\hline No & Kategori & Jumlah & Persentase \\
\hline 1 & Komunitas & 81 & 64,80 \\
2 & Personal & 44 & 35,20 \\
\hline \multicolumn{2}{l}{ Total } & 125 & 100 \\
\hline
\end{tabular}

Target perilaku Komunitas berarti perilaku/sifat baik yang dinilai responden dilakukan untuk komunitas/kepentingan bersama, seperti lingkungan rumah, orang banyak atau masyarakat secara umum. Dengan kata lain, pada target perilaku Komunitas, individu menampilkan perilaku yang sama kepada siapa pun, baik dikenal maupun tidak dikenal. Target perilaku Personal berarti perilaku/sifat baik yang dilakukan individu ditujukan kepada orang tertentu/khusus yang secara personal memiliki keterikatan atau kedekatan, misalnya relasi orang tua dan anak, relasi antara sesama teman, relasi pasangan suami istri, dan lain-lain. Hal ini mengimplikasikan, individu dengan target perilaku Personal belum bisa digeneralisasi akan menampilkan perilaku/sifat yang sama pada orang lain yang secara emosional tidak terlalu dekat bahkan orang asing. Ini disebabkan, kedekatan personal memiliki kelekatan emosional yang mendalam sehingga kecenderungan berbuat baik akan semakin tinggi. Sehingga perilaku individu akan berbeda jika dihadapkan pada situasi bersama orang lain.

Hasil data menunjukkan target perilaku Komunitas lebih tinggi dibanding target perilaku Personal. Hal ini berarti bahwa agar orang dianggap baik dalam masyarakat, maka individu harus mengutamakan kepentingan komunitas/masyarakat di atas kepentingan personal/pribadinya. Selanjutnya, hasil di atas akan disajikan dalam tabulasi silang, yaitu kategori sifat baik dan target perilaku, yang ditunjukkan pada tabel 5 berikut ini. 
Tabel 5.

Tabulasi Silang Orang Baik dan Target Perilaku

\begin{tabular}{clccc}
\hline No & Kategorisasi & Personal & Komunitas & Jumlah \\
\hline \multirow{2}{*}{1} & Kebaikan Hati & 33 & 49 & 82 \\
& & $26,40 \%$ & $39,20 \%$ & $65,60 \%$ \\
2 & \multirow{2}{*}{ Loyalitas } & 11 & 32 & 43 \\
& & $8,80 \%$ & $25,60 \%$ & $34,40 \%$ \\
\hline \multirow{2}{*}{ Total } & 44 & 81 & 125 \\
& & $35,20 \%$ & $64,80 \%$ & $100 \%$ \\
\hline
\end{tabular}

Dari total 125 respon, menunjukkan bahwa respon paling besar yaitu Kebaikan Hati pada target perilaku Komunitas (39,20\%), kemudian Kebaikan Hati pada target perilaku Personal (26,40\%). Hal ini menunjukkan, Kebaikan Hati tetap menjadi nilai kebajikan yang utama dibandingkan Loyalitas, baik pada target perilaku Komunitas maupun Personal. Orang yang dianggap baik adalah orang yang berperilaku baik terhadap anggota komunitas dan sebagai anggota komunitas, tidak hanya sebatas pada relasi personal yang dimilikinya saja. Seperti dijelaskan pada beberapa pernyataan subjek berikut:

"Agus baik terhadap masyarakat sekitar dilihat dari caranya bergaul dan bersosialisasi. Anaknya ramah dan baik kepada teman. Suka menolong dan selalu tersenyum kepada orang lain.” (R.40)

"Bapak Sumanto adalah tetangga depan rumah, gayanya terlihat seperti preman tapi dia baik sekali, keluarga saya baru pindah. Dan Pak Sumanto banyak memberi pertolongan kepada kami, ramah, suka menolong, tidak pelit, dan sangat peka terhadap sesamanya." (R.91)

"Karena bila berkata ia sopan walaupun kepada orang yang lebih muda. Menghargai setiap pendapat orang lain dan apabila dikritik, ia tidak marah justru ia berarti makasih dan berusaha untuk memperbaikinya. Apabila teman kesusahan, ia akan dengan ringan menolong tanpa imbalan. selalu ramah walaupun tidak kenal dan tidak sungkan mengingatkan atau menegur apabila kita salah." (R.102)

Pada konteks budaya Melayu hal ini menunjukkan bahwa kebaikan hati seharusnya dimiliki oleh setiap individu dan diterapkan dalam kehidupan sehari-hari. Seseorang yang baik adalah orang yang mau membantu sesama tanpa pandang bulu, tidak berdasarkan kepentingan personal ataupun kedekatan emosional terhadap orang lain.

\section{DISKUSI}

Studi awal tentang kebajikan dalam konteks budaya Melayu ini, menegaskan hasil studi sebelumnya (Hartshorne \& May, 1928; Hartshorne, May, \& Maller, 1929; Hartshorne, May, \& Shuttleworth, 1930) bahwa faktor situasi lebih penting dalam menjelaskan perilaku moral dibandingkan karakter. Kebajikan sebagai sifat, implementasinya tergantung pada kualifikasi spesifik dan situasional (Hartshorne \& May, 1928; Cawley dkk, 2000). Meskipun beberapa studi yang dilakukan kemudian justru meragukan hasil 
tersebut (Epstein \& O’Brien, 1985; Rushton, 1984), namun dalam studi ini, seperti penjelasan Fowers (2014) kembali dapat ditunjukkan bahwa kebajikan yang spesifik cenderung bergantung pada situasi.

Pada penelitian ini ditemukan bahwa nilai-nilai kebajikan pada situasi penyelesaian masalah berbeda konfigurasinya dibandingkan pada situasi umum. Ketenangan (serenity) dan kecerdasan (resourceful) menjadi nilai-nilai kebajikan yang penting pada situasi penyelesaian masalah. Sementara pada situasi umum, kebaikan hati menjadi nilai kebajikan utama pada masyarakat Melayu.

Hal yang menarik ditunjukkan dalam penelitian ini, kesalehan ditemukan muncul sebagai nilai kebajikan paling rendah dalam konteks budaya Melayu. Meskipun demikian belum dapat dipastikan bahwa ketaatan yang tinggi dengan nilai agama tidak banyak disebut sebagai nilai yang penting dalam relasi sosial dibandingkan dengan kebaikan hati. Kemungkinan karena nilai kebaikan hati yang cakupannya lebih luas dan umum, sementara tidak ada pertanyaan elaborasi untuk mendapatkan fakta bahwa kesalehan juga merupakan kebaikan hati.

Akan tetapi, temuan ini tetap dapat menegaskan, dalam hidupnya masyarakat Melayu memposisikan relasi sosial sebagai hal yang utama. Individu yang dinilai baik adalah mereka yang mampu menolong dan peduli dengan sesama, ramah dan sopan dalam bertutur kata serta kesediaan memberi dan menghormati orang lain.

Dalam hal target perilaku baik, penelitian ini dapat menjelaskan bahwa bagi orang Melayu, perilaku baik lebih diharapkan ditujukan pada komunitas dibandingkan personal. Setiap individu diharapkan menampilkan perilaku baik kepada siapa pun dalam komunitasnya. Bahkan loyalitas terhadap komunitas, dalam arti komitmen terhadap nilai-nilai dan ide kebaikan bersama, ternyata bukan hal utama dibandingkan dengan kebaikan hati yang bersifat relasional. Individu yang setia dan bertanggung jawab akan peran dan tugasnya di dalam kelompok masyarakat belum bisa dikatakan baik ketika tidak ramah, sopan dan menolong antar sesama. Dalam konteks budaya Melayu, hal ini menuntut setiap individu memiliki kebaikan hati pada siapa pun meskipun dengan individu yang tidak memiliki kedekatan/ikatan emosional.

Seperti dijelaskan oleh Fowers (2012), nilai kebajikan sebagai konsep multidimensional, juga meliputi character strength dan kaitannya dengan kehidupan yang baik (Fowers, 2012). Dalam konteks budaya Melayu, untuk mencapai kehidupan yang baik tersebut, kebaikan hati lebih diharapkan dibandingkan komitmen, partisipasi dan kontribusinya dalam masyarakat.

\section{SIMPULAN DAN SARAN}

\section{Simpulan}

Penelitian ini merupakan penelitian awal mengenai nilai kebajikan di Indonesia khususnya pada budaya Melayu. Beberapa kesimpulan dapat ditarik dalam penelitian ini. Pertama, dalam situasi umum 
nilai kebajikan pada budaya Melayu tidak berbeda dengan klasifikasi nilai kebajikan oleh Seligman (2012). Kebaikan hati muncul sebagai nilai kebajikan utama yang merupakan nilai moral yang dianut dalam budaya Melayu. Kebaikan hati merupakan bentuk nilai yang berada dalam relasi dengan orang lain. Temuan ini menyiratkan, relasi sosial merupakan hal penting dalam budaya Melayu.

Kedua, penelitian kembali menegaskan peran situasi spesifik terhadap nilai kebajikan. Pada konteks sosial yang berbeda maka nilai kebajikan yang dominan muncul juga akan berbeda. Oleh karena itu, penelitian ini sejalan dengan kajian dalam psikologi sosial sebelumnya mengenai kekuatan situasi dalam perwujudan nilai kebajikan (Benkler \& Nissenbaum, 2006; Kamtekar, 2004). Dalam penelitian ini, konteks situasi yang dibentuk adalah situasi dalam menghadapi masalah dengan nilai kebajikan utama yang muncul yaitu ketenangan hati (serenity) dan kecerdasan kognitif (resource fulness).

Ketiga, nilai kebajikan yang hidup dalam masyarakat dapat digolongkan dalam dua klasifikasi utama yaitu kebaikan hati dan loyalitas. Pada konteks budaya Melayu, kebaikan hati dinilai lebih penting daripada loyalitas. Hal ini memberikan implikasi penting dalam memahami perilaku masyarakat Melayu. Keempat, dalam target penyampaian perilaku baik, komunitas lebih unggul daripada personal. Artinya, individu yang baik adalah mereka yang mau menolong siapa pun baik dikenal maupun tidak dikenal bukan mau menolong dikarenakan adanya kepentingan personal ataupun kedekatan emosional dengan orang lain.

\section{Saran}

Penelitian ini merupakan studi awal mengenai kajian kebajikan di dalam psikologi. Penelitian berikutnya, dapat melakukan hal yang sama dalam konteks budaya berbeda. Selain itu, pemberian konteks situasi dalam penelitian ini hanya satu sehingga komparasi antar situasi spesifik mustahil untuk dilakukan. Penelitian akan lebih menarik jika dilakukan dalam beberapa konteks situasi yang berbeda sehingga dinamika perwujudan kebajikan dalam perilaku di masyarakat akan lebih bervariasi. Kajian mengenai variasi wujud nilai kebajikan antar situasi akan menjadi pembahasan yang menarik untuk diteliti.

\section{REFERENSI}

Allport, G. W. (1937). Personality: A psychological interpretation. New York, NY: Holt.

Annas, J. (2003). Virtue Ethics and Social Psychology. A Priori, 2, 20-33

Baehr, J. (2013). Educating for Intellectual Virtues: From Theory to Practice. Journal of Philosophy of Education, 47(2), 248-262.

Benkler, Y., \& Nissenbaum, H. (2006). Commons-based Peer Production and Virtue. The Journal of Political Philosophy, 14(4), 394-419. 
Cawley, M.J., Martin, J.E., \&Johnson, J.A. (2000). A virtues approach to personality. Personality and Individual Differences, 28(2000), 997-1013.

Cornwell, J.F McCullough. (2014). The Principled Pursuit of Happiness: Virtue's Role in Moral Psychology (Dissertation). New York, NY: Columbia University.

Dahlsgaard, K., Peterson, C., Seligman, M.E.P. (2005). Shared Virtue: The Convergence of Valued Human Strengths Across Culture and History. Review of General Psychology, 9(3), 203-213.

Emmons, R. A. (2003). Personal Goals, Life Meaning, And Virtue: Wellsprings Of A Positive Life. Dalam C.L.M. Keyes (Ed.), Flourishing: The positive person and the good life (hlm. 105-128). Washington, DC: American Psychological Association.

Epstein, Seymour \& O’Brien, Edward, J. (1985). The person-situation debate in historical and current perspective. Psychological Bulletin,98(3), 513-537.

Fowers, B. J. (2005). Virtue and Psychology: Pursuing Excellence in Ordinary Practices. Washington, DC: APA Press.

(2012). Placing Virtue and the Human Good in Psychology. Journal of Theoretical and Philosophical Psychology, 32(1), 1-9.

(2012). An Aristotelian framework for the human good. Journal of Theoretical and Philosophical Psychology, 32(1), 10-23.

(2014). Assessing Virtue: Lessons from Subfields of Psychology. These are unpublished conference papers for the Jubilee Centre for Character and Values at Oriel College, Thursday 9th - Saturday 11th January 2014.

Haidt, J. (2012). The Righteous Mind: Why Good People Are Divided By Politics And Religion. New York, NY: Pantheon Book.

Haidt, J. \& Joseph, C. (2004). Intuitive ethics: How innately prepared intuitions generate culturally variable virtues. Daedalus Fall, 55-66.

Hartshorne, H., \& May, M. A. (1928). Studies in the nature of character: Studies in deceit (vol.1). New York, NY: Macmillan.

Hartshorne, H., May, M. A., \& Maller, J. B. (1929). Studies in the nature of character: Studies in selfcontrol, vol. 2. New York, NY: Macmillan.

Hartshorne, H., May, M. A., \& Shuttleworth, F. K. (1930). Studies in the nature of character. Studies in the organization of character (vol. 3). New York, NY: Macmillan.

Jost, J.T. \& Jost, L.J. (2009). Virtue ethics and the social psychology of character: Philosophical lessons from the person-situation debate. Journal of Research in Personality, 43(2009), 253-254.

Kamtekar, R. (2004). Situationism and Virtue Ethics on the Content of Our Character.Ethics, 114, 458-491. 
Kramer, D. A. (2000). Wisdom as a classical source of human strength: Conceptualization and empirical inquiry. Journal of Social and Clinical Psychology, 19(1), 83-101.

Oudenhavan, J.P., Raad, B., Carmona, C., Helbig, A., Linden, M. (2012). Are Virtues Shaped by National Cultures or Religions?. Swiss Journal of Psychology, 71(1), 29-34.

Oudenhoven, J.P., Raad, B., Timmerman, M.E., Askevis-Leherpeux, F., Boski, P., Carmona, C., Choubisa, R., Dominguez, A.C., Bye, H.H., Kurlyo, A., Lahnmann, C., Mastor, K., Selenko, E., Slezackova, A., Smoith, R., Tip, L., Yik, M. (2014). Are virtues national, supranational, or universal?. SpringerPlus, 3(223), 1-12.

Peterson, C. \& Seligman, M.E.P. (2004). Character Strengths and Virtue: A Handbook and Classification. New York, NY: Oxford University Press.

Rushton, J. P. (1985). Differential K theory: The sociobiology of individual and group differences. Personality and Individual Differences, 6(4), 441-452.

Schnall, E., Schiffman, M., \& Cherniak, A. (2014). Values That Transcend: Positive Psychology In Jewish Texts And Tradition. In C. Kim-Prieto (Ed.), Religion and spirituality across cultures. New York, NY: Springer.

Seligman, M.E.P. (2002). Authentic Happiness: Using the New Positive Psychology to Realize Your Potential for Lasting Fulfillment. New York, NY: Free Press/Simon and Schuster.

Shryack, J., Steger, M.F., Krueger, R.F., \&Kallie, C.S. (2010). The structure of virtue: An empirical investigation of the dimensionality of the virtues in action inventory of strengths. Personality and Individual Differences, 48(2010), 714-719.

Walshe, M. (1995). The Long Discourses of the Buddha: A Translation of Digha Nikaya (Teachings of the Buddha). Somerville, MA: Wisdom Publications. 